\title{
Predation risk effects on fitness related measures in a resident bird
}

\author{
Robert L. Thomson, Jukka T. Forsman, Mikko Mönkkönen, Markku Hukkanen, Kari Koivula, Seppo Rytkönen \\ and Markku Orell
}

\begin{abstract}
Thomson, R. L., Forsman, J. T., Mönkkönen, M., Hukkanen, M., Koivula, K., Rytkönen, S. and Orell, M. 2006. Predation risk effects on fitness related measures in a resident bird. - Oikos 113: 325-333.
\end{abstract}

\begin{abstract}
Predation risk is thought to be highly variable in space and time. However, breeding avian predators may create locally fixed and spatially fairly predictable predation risk determined by the distance to their nest. From the prey perspective, this creates predation risk gradients that potentially have an effect on fitness and behavioural decisions of prey. We studied how breeding avian predators affect habitat selection (nest location) and the resulting fitness consequences in a northern population of resident willow tit (Parus montanus). Data included 429 willow tit nests over a four year period in a landscape containing a total of 33 avian predator nests. Willow tit nests were located randomly in the landscape and no predator avoidance in habitat selection or emptying of territories in proximity to predators was observed. Nestling size, however, was positively associated with distance from predator nests $(n=252)$. Nestling mass and wing length were about $4.5 \%$ smaller close to predator nests compared to nestlings raised far from predator nests. Tarsus length also exhibited a positive relationship with increasing distance from predator nest but this was limited to habitats of young forests and pine bogs or dense mixed forests (4\% increase). It is likely that habitat structural complexity influenced the perception of predation risk in different habitats. Our results indicate that willow tits do not provide reliable cues of predator free habitats for settling migrants. Nonetheless, breeding avian predators may create predictable predation risk in the landscape which is an important factor affecting reproductive success and potentially the demography of prey populations.
\end{abstract}

R. L. Thomson, M. Hukkanen, K. Koivula, S. Rytkönen and M. Orell, Dept of Biology, Univ. of Oulu, PO Box 3000, FIN-90014 Oulu, Finland (robert.thomson@oulu.fi). - J. T. Forsman, Dept of Ecology and Evolution, Evolutionary Biology Centre, Uppsala Univ., Norbyvägen $18 d$, SE-75236 Uppsala, Sweden. - M. Mönkkönen, Dept of Biological and Environmental Science, POB 35, FIN-40014 University of Jyväskylä, Finland.

Predation risk influences prey survival and fitness, and is therefore important in shaping animal behaviour and community organisation (Lima 1998a). In avian communities, for example, predation risk on adults may affect the spatial dispersion of foraging birds (Forsman et al. 2001) resulting in the formation of mixed species foraging aggregations (Forsman et al. 1998b, Morse 1977). In addition, during the breeding season, prey densities may decrease in the vicinity of breeding avian predators (Sodhi et al. 1990, Suhonen et al. 1994,
Hromada et al. 2002, Thomson et al. 2006). This may be due to direct predation effects of the predator, but may also be due to predator avoidance where, through a habitat selection strategy, birds avoid breeding near avian predator nests where predation risk is higher (Norrdahl and Korpimäki 1998).

In forested habitats, evidence suggests that small passerines nesting close to avian predators like sparrowhawk (Accipiter nisus L.), may incur disadvantages through decreased survival, reproductive success and 
fledgling mass (Geer 1978, Adriaensen et al. 1998, Dhondt et al. 1998). Close presence of breeding sparrowhawks and other avian predators clearly increases the pressure on nesting variables (Geer 1982, Sasvári and Hegyi 1998, Götmark 2002). In contrast, several studies indicate that predators of adult birds may provide benefits to prey nesting nearby, for example, protection against destructive nest predators (Norrdahl et al. 1995, Bogliani et al. 1999, Quinn et al. 2003). In Accipiter spp., new information is emerging that they may provide such protection (Mönkkönen et al. 2000). Therefore, despite the amount of literature dealing with the effects of predation risk in birds, surprisingly large gaps still exist in our understanding, particularly at the macro-habitat scale (Lima 1998b), of the distribution of nests and nonlethal fitness costs or protection benefits of settling under different predation risks (Lima 1998a).

It is clear that the landscape, from a prey perspective, shows considerable heterogeneity in predation risk. The crucial question is whether predation risk shows any predictability so that prey individuals could respond to it accordingly. Breeding avian predators could create such predictability when their nests form the central site from which predation risk stretches into the surrounding landscape (Suhonen et al. 1994, Norrdahl and Korpimäki 1998, Hromada et al. 2002). Gradients of predation risk are created by hawks commuting between hunting areas and the nest and are determined by predator encounter rates, which will be higher closer to the avian predator nests (Forsman et al. 2001, Thomson et al. 2006). This will result in increasing perceived predation risk with decreasing distance to the nest. Thus far, evidence of non-random prey dispersion relative to breeding predators comes from structurally simple environments (Norrdahl and Korpimäki 1998, Hromada et al. 2002). The impact of breeding predators in forested habitats and the role of habitat structural complexity therefore remains unknown (Whittingham and Evans 2004).

In this study, accurate knowledge of the nesting sites and breeding success of a willow tit (Parus montanus Conrad) population and their avian predators provides an opportunity to test the existence of a predation risk landscape in a resident bird species which holds established territories in the landscape year-round. Willow tits are ideal among cavity nesters as they are excavators breeding in natural sites at natural densities. Furthermore, three different avian predators also nest within the landscape in varying numbers each year. During breeding these predators feed to differing degrees on passerine birds, sparrowhawk almost entirely (Newton 1986, Rytkönen et al. 1998), pygmy owl (Glaucidium passerinum L.) between 43\% and 69\% (Jędrzejewska and Jędrzejewski 1993, Kullberg 1995) and Tengmalm's owl (Aegolius funereus L.) around 16\% (Korpimäki 1981).
We aim to test whether the vicinity of breeding predators should be avoided, because high predation risk negatively affects breeding birds, or alternatively, whether breeding predators may be sought as neighbours due to protective benefits they may provide. Therefore, we examined how willow tit nests were located relative to avian predator nests in the landscape. The location of willow tit nests relative to breeding predators also allows testing the hypothesis whether residents provide reliable cues to safe habitats for settling migrants, a proposed mechanism for the heterospecific attraction hypothesis (Mönkkönen et al. 1999). Finally, we aim to test nesting success and nestling quality in relation to distance from predator nest. How does increased lethal and non-lethal predation risk determined by prey dispersion relative to predator dispersion effect fitness consequences of willow tits and what role does habitat structure play in this relationship.

\section{Methods}

\section{Field procedures}

The $23 \mathrm{~km}^{2}$ study area, near Oulu in northern Finland $\left(65^{\circ} \mathrm{N}, 25^{\circ} 30^{\prime} \mathrm{E}\right)$, consists of young or middle-aged forests of birch Betula spp., Norway spruce (Picea abies L.) and Scots pine (Pinus sylvestris L.). Forestry, natural bogs and lakes result in a fragmented landscape (Orell and Ojanen 1983). The willow tit population in this area has been studied since 1975 (Orell and Koivula 1988). For this study, willow tit nest data for years 1996-1999 was used because during this time we located all breeding avian predators in the study area by carefully searching all known and suitable nesting sites. In total 33 avian predators bred in the landscape during these years although only sparrowhawks bred regularly in each year, while the owl species, owing to their larger dependence on vole numbers, bred in two of the four years (Table 1).

Intensive monitoring of the willow tit population takes place before and during every breeding season (from early April to late June). During monitoring, taped territorial song of the willow tit was played back throughout the study area. This allows us to identify all territory holders (and non-breeding individuals) and with thorough observations of territory holders allows us to find every nest within the habitat. Breeding data from each nest, timing of egg-laying, clutch size and hatching date were routinely checked throughout the season. Finally, when the brood's oldest nestlings were 13 days old, all young were ringed and their body mass, wing, tail and tarsus lengths measured using a standard procedure across all nests (Orell et al. 1999).

Following laying of the second egg in willow tit nests, a sturdy wire-mesh cage with a small opening was placed around nests, which allowed parents to enter their nest but prevented nest predation by woodpeckers or jays. 
Table 1. Number of willow tit and avian predator nests in the study site in each year.

\begin{tabular}{|c|c|c|c|c|}
\hline \multirow[t]{2}{*}{ Species } & \multicolumn{4}{|c|}{ Number of nests in different years (unsuccessful nests) } \\
\hline & 1996 & 1997 & 1998 & 1999 \\
\hline Willow tit & 87 (13) & $88(18)$ & $114(21)$ & $140(29)$ \\
\hline Sparrowhawk & 8 & 5 & 5 & 6 \\
\hline Pygmy owl & 2 & - & - & 1 \\
\hline Tengmalm's owl & 6 & - & - & - \\
\hline
\end{tabular}

Therefore, in the study area, previously high willow tit nest predation rates (Orell and Ojanen 1983) have been eliminated, although indirect or perceived nest predation risks may still influence parental behaviour and resulting nestling quality. This setup therefore provides a unique opportunity to examine the direct and indirect effects of predation on adult habitat selection and reproductive success.

\section{Data procedures}

The study area was divided into $100 \times 100 \mathrm{~m}$ squares. Using aerial photographs and personal knowledge of the area, each square was classified into 1 of 5 habitat categories 1) medium aged coniferous forest consisting of different mixtures of spruce and pine 2) deciduous forest 3) young forest stand (trees $<5 \mathrm{~m}$ ) or pine bog 4) dense mixed forest and 5) unsuitable nesting habitat (treeless bogs, lakes and clear-cuts). If a square contained two or more habitat types, the habitat most preferred for willow tit nesting was used. Habitat classifications were the same across years, except in those squares where clear-cutting had occurred, leaving them unsuitable. Thus the number of squares suitable for breeding decreased slightly in each consecutive year. In each year, the distance of every square (and therefore every nest) to the nearest predator nest was determined, ranging from $0 \mathrm{~km}$ for squares that contained predator nests to a maximum of $2.3 \mathrm{~km}$.

\section{Statistical analyses}

Willow tit nest distribution $(n=429)$ in relation to three groups of predators, sparrowhawks, owls and all predators together was tested for each year. Categories termed "all predators" in the resampling results refer to the combined sparrowhawk and owl effect; however, in 1997 and 1998, in absence of owls, "all predators" results mirror those of sparrowhawk results. A re-sampling programme (Blank et al. 2001) was used to randomly generate squares, with replacement, in the landscape in order to create a null model of willow tit nest location relative to breeding avian predators. The resampling included two steps, 1) the random selection of a square and 2) the probability of that square being selected by a willow tit. For the second step, each square had a habitat specific probability for it to be included in the final sample indicating the preference of willow tits for the habitat present within that square for each specific year. The yearly habitat preferences were calculated by finding the proportion of nests within each habitat based on the availability of that habitat in the landscape. The proportions were then determined in relation to the most preferred habitat, with the most preferred habitat having a value of 1 . The number of squares randomly generated was equal to the number of willow tit nests in that year. For each run, consisting of 1000 simulations, the average distance of the randomly generated squares from breeding predators was calculated and compared with the mean observed distance of nests from breeding predators in the landscape. If willow tit nest locations show predator avoidance then expected distances should rarely be larger than the observed distances. Resampling analysis was repeated with two other data sets. Firstly, using only second year (experienced) birds' nests and secondly, using the previous year's predator nest location to determine current year's willow tit nest distribution (possible in years 1997-1999).

The effect of distance to the nearest avian predator nests (predation risk) was tested, firstly, on the fate of the nest (direct effects) and secondly, on parental and nestling quality (indirect effects). Of the 429 willow tit nests, 81 nests were unsuccessful (no young fledged). A further 14 nests had lost either parent during the nestling stage or were not measured when nestlings were 13 days old. These nests were excluded from nestling quality analyses, as they were not suitable or comparable measures of nestling size when analysing the influence of non-lethal predation risk. Nestling size measures were averaged within a nest and this was used as the unit in analysis. Some nests, however, clearly showed extremely small values indicating some unknown problem with the nest. We suspect that these nests had a parent bird missing but, because data was not collected specifically for the purpose of this study, this was not noted at the time of nestling measurement. To identify the worst outliers we used a modified z-score, a method based on outlier resistant estimators (Müller 2000, Burke 2001). The test heuristic states that an observation with an absolute modified $z$-score $\geq 3.5$ is an outlier. We excluded observations that were labelled as outliers in one or more of the nestling size measures (mass, tarsus or wing length, $n=9$ ). We feel it is biologically sensible 
and justified to exclude these nests from the analysis of indirect predation effects.

Nests were pooled across all four years. Fortunately, the parent birds of each nest are known and we removed all nests with exactly the same parent birds in years subsequent to that pair first breeding. Therefore, only the first nest of any pair is included in the analysis to avoid non-independence of points. The same bird breeding in a subsequent year but with a different partner is regarded as an independent observation. A total of 71 nests were removed.

For clutch size, number nestlings fledged and nestling quality measures (dependent variables), an ANCOVA was performed $(n=252)$. Distance to the nearest avian predator nest and squared distance (to test for nonlinear/unimodal effects resulting from a possible tradeoff between costs and possible benefits) were entered as covariates, year and habitat as random and fixed factors respectively. Furthermore, because the date of first egg and clutch size may affect nestling quality variables, they were included as covariates in nestling quality ANCOVA models in order to control for their effect and reveal the true effect of predation risk. We transformed dependent variables where necessary in order to keep ANCOVA assumptions of homogeneity of variances and normality of residuals. In every model we included the interaction between distance to nearest predator nest and habitat. The mixed-use nature of the study area results in different habitats of differing structural complexity and significance of this two-way interaction would indicate that the effect of distance is not consistent among these habitats. We used backward elimination if the interaction or quadratic terms were non-significant in order to simplify the models.

One may argue that each willow tit nest at a given distance from a predator nest cannot be considered independent data point because they may share a common predator. Scheiner (2001), however, suggests biologically separate units, such as broods, can be regarded as sampling units, and he argues against the over interpretation of the pseudoreplication issue. Nevertheless, to test for a pseudoreplication problem in our study we re-analysed nestling quality variables using an alternative approach. We treated predator nests within a year as independent and assigned each willow tit nest to its nearest predator. Altogether there were 33 predator nests during 1996-99 (Table 1). For those predator nests influencing more than three tit nests $(\mathrm{n}=$ 21), we ran a regression analysis to assess the role of distance in relation to the nestling quality variable. Number of willow tit nests per predator varied between 4 and 17. Model for wing length only contained distance but for mass we also included clutch size because clutch size was significant in the full model. We used metaanalysis (Gurevitch and Hedges 1993, Cooper and Hedges 1994) to make quantitative summary of the effects of distance on the wing length and mass of the fledglings. In other words, we used each predator nest as independent replicate and assessed if fledgling parameters are consistently and significantly associated with distance to the nearest predator. "Effect size" in a metaanalysis is defined as the level of statistical relationship between two variables of interest. We opted for the Pearson correlation coefficient, $r$, as a measure of association between distance and nestling quality. We transformed the results of regression analyses into ztransformed correlation coefficients using the procedure outlined in Cooper and Hedges (1994). Meta-analysis was run using MetaWin 2.0 (Rosenberg et al. 1997) to yield an estimate of cumulative effect size. Cumulative effect size can be considered significantly different from zero if its $95 \%$ confidence interval does not include zero. Total heterogeneity, $\mathrm{Q}_{\mathrm{T}}$, measures if effect sizes are homogeneous. A significant $\mathrm{Q}_{\mathrm{T}}$ indicates that the variance among effect sizes is greater than expected by sampling error.

\section{Results}

Compared with the average distance to predator nest of randomly resampled positions, observed willow tit nests were located randomly in the landscape (Table 2). The proportion of expected distances being greater than observed distances varied between $0.47-0.52$ for sparrowhawk and $0.42-0.70$ for all predators in 1996, 1998 and 1999. It is therefore clear that willow tit nests were not located farther from predators than expected by chance. In 1997, expected distances were frequently larger than observed distances ( $p$-value $=0.83$ ) indicating that ob-

Table 2. Comparison of the distances from the nearest predator nest between the observed $\left(\mathrm{R}_{\mathrm{obs}}\right)$ and expected/resampled $\left(\mathrm{R}_{\mathrm{exp}}\right)$ values for the three predator groups. $R_{\text {obs }}$ and $R_{\text {exp }}$ values show mean distance to predator nest in kilometres $(\mathrm{km})$. $P$ represents the frequency with which resampled values are greater than the observed value (opposite to that predicted). A p-value of 0.05 (equals 50 of 1000 iterations) would show significant avoidance of predator nests in observed values.

\begin{tabular}{|c|c|c|c|c|c|c|c|c|c|}
\hline \multirow[t]{2}{*}{ Year } & \multicolumn{3}{|c|}{ Sparrowhawk } & \multicolumn{3}{|c|}{ Owls } & \multicolumn{3}{|c|}{ All predators } \\
\hline & $\mathrm{R}_{\mathrm{obs}}$ & $\mathrm{R}_{\exp }$ & $\mathrm{P}$ & $\mathrm{R}_{\mathrm{obs}}$ & $\mathrm{R}_{\mathrm{exp}}$ & $\mathrm{P}$ & $\mathrm{R}_{\text {obs }}$ & $\mathrm{R}_{\mathrm{exp}}$ & $\mathrm{P}$ \\
\hline 1996 & 0.74 & 0.73 & 0.47 & 0.85 & 0.85 & 0.56 & 0.58 & 0.60 & 0.70 \\
\hline 1997 & 0.94 & 0.99 & 0.83 & - & - & - & 0.94 & 0.99 & 0.83 \\
\hline 1998 & 0.98 & 0.98 & 0.50 & - & - & - & 0.98 & 0.98 & 0.50 \\
\hline 1999 & 0.90 & 0.90 & 0.52 & 2.46 & 2.66 & 0.98 & 0.80 & 0.80 & 0.42 \\
\hline
\end{tabular}


served nest dispersion trend was slightly clumped. In 1999, there was a significant clumping of willow tit nests around the single pygmy owl nest present in that year (Table 2). Using the nests of only experienced second year willow tits in analysis, as well as using the previous year's predator nest locations to determine current year willow tit nest distribution also yielded no significant clumping or avoidance around predator nests (unpubl.).

Logistic regression indicates that distance to predator nests had no influence (linear or non-linear) in determining willow tit nest success (logistic regression model: $\left.\chi_{8}^{2}=14.28, p=0.08\right)$. Indeed, nesting failures were on average slightly further from predators than successful nests in all years except 1996 (overall: (mean \pm SE) nest failures $0.89 \mathrm{~km} \pm 0.005, \mathrm{n}=81$; successful nests, 0.82 $\mathrm{km} \pm 0.001, \mathrm{n}=348$ ).

Clutch size did not vary with distance from predator nests $\left(\mathrm{F}_{1,243}=0.56, \mathrm{p}=0.457\right)$. This suggests that parental quality did not differ with distance from predator nests (similar non-significant results were obtained using date of first egg). Similarly, distance to predator nests did not influence the number of nestlings fledged from nests (squared transformation; $\mathrm{F}_{1,243}=0.32, \mathrm{p}=0.573$ ). Indeed, both clutch size and the number of fledged nestlings were largely determined by the date of first egg laid (clutch size: $\mathrm{F}_{1,243}=33.51, \mathrm{p}=0.0001$; fledged nestlings: $\left.\mathrm{F}_{1,243}=7.48, \mathrm{p}=0.007\right)$.

In the ANCOVA models, with clutch size and date of first egg controlled for, distance to predator nest significantly explained nestling wing length (squared wing length transformation) and mass (cubed mass transformation) (Table 3). Willow tit nests ranged from between $0.1-2.0 \mathrm{~km}$ from predator nests. In this range of distance, wing length increased on average by $4.7 \%$, while nestling mass increased by $4.5 \%$ (Fig. 1). For tarsus length there was a significant interaction between distance to predator nests and habitat type, which indicates that the response of tarsus length is not parallel within different habitats. We therefore performed ANCOVA separately in the different habitats (habitat $1, \mathrm{n}=$ 83; habitat 2, $\mathrm{n}=30$; habitat $3, \mathrm{n}=54$; habitat $4, \mathrm{n}=85$ ). We found that in pine bogs and young forests (habitat 3 ) and in dense mixed forest (habitat 4), distance to predator nests significantly influenced tarsus length (Table 4). Within the range of nest distances in these habitats, average tarsus length increased by about $4 \%$ with increasing distance (Fig. 2), whereas there were no increases in other habitats (Fig. 2). Indeed, if nestling mass and wing length variables are analysed separately for habitats, similar results are found to those of tarsus length. For both variables only in habitats of pine bogs and young forests (habitat 3) and dense mixed forests (habitat 4) does distance to predator nests emerge as a significant or close to significant explanatory variable. For pine bogs and young forests (wing: $F_{1,47}=3.12$, $\mathrm{p}=0.08,8.8 \%$ increase; mass: $\mathrm{F}_{1,47}=5.71, \mathrm{p}=0.02$, $10.3 \%$ increase) and for dense forests (wing: $F_{1,78}=$ 5.02, $\mathrm{p}=0.03,9.5 \%$ increase; mass: $\mathrm{F}_{1,78}=4.95, \mathrm{p}=$ $0.03,8.6 \%$ increase).

Meta-analysis showed that cumulative effect size for fledgling wing length was larger than zero (estimate = $0.14 ; 95 \%$ confidence interval 0.01 to 0.30 ) indicating that distance from predators nests has a significant positive overall effect on wing length. Total heterogeneity was not significant $\left(\mathrm{Q}_{\mathrm{T}}=13.49\right.$, $\left.\mathrm{df}=20, \mathrm{p}=0.86\right)$ suggesting that the results from the 21 independent nests are consistent. For fledgling mass, the effect size was positive but not quite different from zero (estimate = $0.12 ; 95 \%$ confidence interval -0.05 to $0.33 ; \mathrm{Q}_{\mathrm{T}}=$ 19.27, $\mathrm{df}=20, \mathrm{p}=0.50$ ). Given that there are multiple

Table 3. Summary ANCOVA (type III ss) table showing the response of transformed chick size (mass and wing length) to predation risk (distance to predator nest). Clutch size and date of first egg are entered as covariates in order to control for the effect of parental quality and brood size and reveal the independent effect of predation risk (distance to predator nest) on nestling quality.

\begin{tabular}{|c|c|c|c|c|c|}
\hline \multirow[t]{2}{*}{ Source of variation } & \multicolumn{2}{|c|}{ Wing length $^{\mathrm{a}}$} & \multirow[t]{2}{*}{$\operatorname{MS}\left(\times 10^{5}\right)$} & \multirow[t]{2}{*}{$\mathrm{F}$} & \multirow[t]{2}{*}{$\mathrm{P}$} \\
\hline & $\mathrm{df}$ & $\mathrm{B} \pm \mathrm{SE}$ & & & \\
\hline Model $\left(\mathrm{R}^{2}=0.123\right)$ & 9 & & 1.683 & 3.785 & 0.000 \\
\hline Habitat & 3 & & 0.04 & 0.090 & 0.965 \\
\hline Year & 3 & & 2.385 & 5.363 & 0.001 \\
\hline Distance to nest & 1 & $71.39 \pm 33.74$ & 1.992 & 4.479 & 0.035 \\
\hline Date of first egg & 1 & $0.347 \pm 3.32$ & 0.0049 & 0.011 & 0.917 \\
\hline Clutch size & 1 & $-4.81+11.22$ & 0.082 & 0.184 & 0.668 \\
\hline \multirow[t]{2}{*}{ Error } & 242 & & 0.445 & & \\
\hline & Mass ${ }^{b}$ & & & & \\
\hline $\operatorname{Model}\left(\mathrm{R}^{2}=0.111\right)$ & 9 & & 1.784 & 3.359 & 0.001 \\
\hline Habitat & 3 & & 0.357 & 0.672 & 0.570 \\
\hline Year & 3 & & 0.747 & 1.406 & 0.242 \\
\hline Distance to nest & 1 & $88.75 \pm 36.87$ & 3.078 & 5.795 & 0.017 \\
\hline Date of first egg & 1 & $1.68+3.62$ & 0.114 & 0.215 & 0.644 \\
\hline Clutch size & 1 & $-24.68 \pm 12.26$ & 2.155 & 4.056 & 0.045 \\
\hline Error & 242 & & 0.531 & & \\
\hline
\end{tabular}

a squared wing transformation.

b cubed mass transformation. 

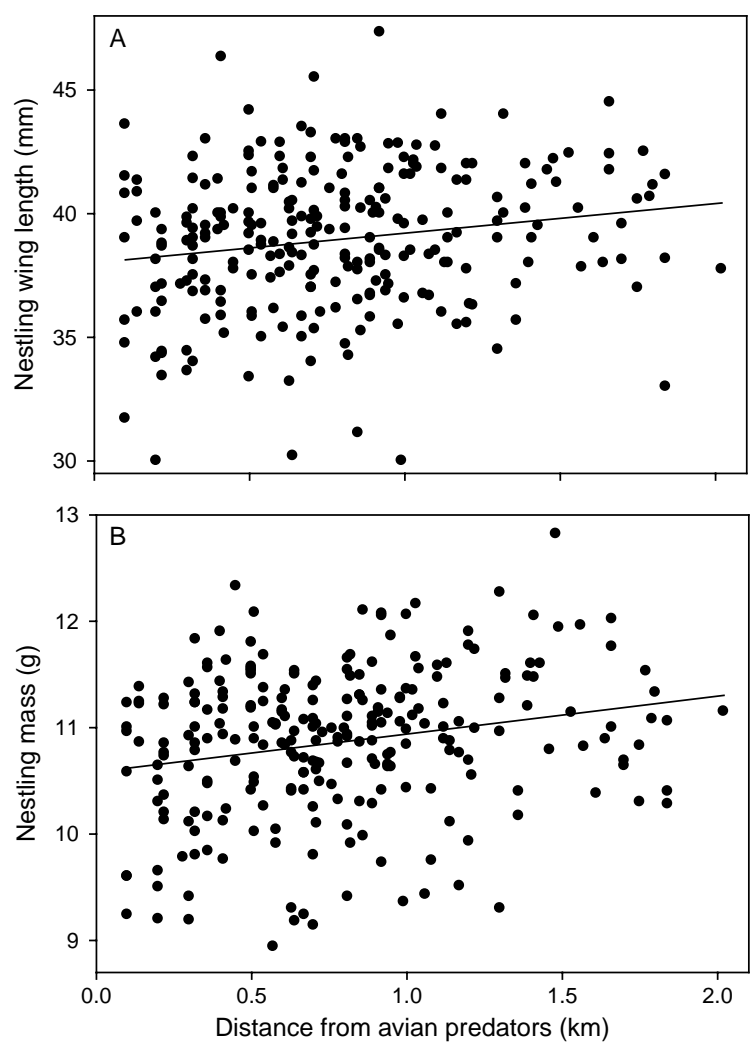

Fig. 1. Simple regression relationship between the distance from the nearest avian predator nest and untransformed (A) wing length and (B) nestling mass.

factors affecting fledgling body mass other than distance from the nearest predator, we still consider this result to provide consistent indication that fledgling mass increases with the distance from the nearest predator. Furthermore, because the overall effect size for mass was positive we think that the non-independence of data points is not seriously confounding the results of the overall analysis presented in Table 3.

\section{Discussion}

Our study shows that, although willow tit nests were located randomly with respect to avian predator nests in the landscape, the spatial anchoring of non-lethal predation risk that stems from central-place foraging avian predators does affect fitness related measures. We found that willow tit nestling size, as indicated by wing and tarsus length, significantly increased with distance from breeding avian predators. This result supports the concept of a predation risk landscape that creates predictable non-lethal predation risk gradients within the environment (Thomson et al. 2006). These gradients will be important in understanding the variation in behaviour and demography of prey populations at larger spatial scales.

Complete nest failures were not related to distance from predators, however, in successful nests larger chicks (approximately $4.5 \%$ ) were produced in nests far from predators than those nearby. Variations in the quality parameters of offspring are also important in terms of individual fitness. It is accepted that poor or stressful conditions result in smaller nestlings (Merilä 1997) and that nestling size, resulting from early development, determines future survival and fitness (Lindström 1999, Brotons and Broggi 2003). In willow tit, for example, wing and tarsus length may determine dominance status within sex and age classes (Lahti et al. 1996), while dominance in turn determines winter survival (Koivula et al. 1996). Furthermore, wing length may even have priority during growth over tarsus length, as fledglings need to ensure that they leave the nest with the rest of the brood (Nilsson and Gårdmark 2001).

Table 4. Summary ANCOVA (type III ss) table showing the response of tarsus length to predation risk (distance to predator nest) in pine bogs and young forest (habitat 3) and dense mixed forests (habitat 4). Clutch size and date of first egg are entered as covariates in order to control for the effect of parental quality and brood size and reveal the independent effect of predation risk (distance to predator nest) on nestling quality.

\begin{tabular}{|c|c|c|c|c|c|}
\hline \multirow[t]{2}{*}{ Source of variation } & \multicolumn{2}{|c|}{ Tarsus length } & \multirow[t]{2}{*}{ MS } & \multirow[t]{2}{*}{$\mathrm{F}$} & \multirow[t]{2}{*}{$\mathrm{P}$} \\
\hline & $\mathrm{df}$ & $\mathrm{B} \pm \mathrm{SE}$ & & & \\
\hline \multicolumn{6}{|c|}{ Pine bogs and young forest } \\
\hline Model $\left(\mathrm{R}^{2}=0.242\right)$ & 6 & & 0.312 & 2.497 & 0.035 \\
\hline Year & 3 & & 0.312 & 2.499 & 0.071 \\
\hline Distance to nest & 1 & $0.307 \pm 0.13$ & 0.702 & 5.617 & 0.022 \\
\hline Date of first egg & 1 & $0.012 \pm 0.01$ & 0.151 & 1.212 & 0.277 \\
\hline Clutch size & 1 & $0.057 \pm 0.05$ & 0.181 & 1.452 & 0.234 \\
\hline Error & 47 & & 0.125 & & \\
\hline \multicolumn{6}{|l|}{ Dense mixed forests } \\
\hline Model $\left(\mathrm{R}^{2}=0.175\right)$ & 6 & & 0.498 & 2.754 & 0.018 \\
\hline Year & 3 & & 0.345 & 1.904 & 0.136 \\
\hline Distance to nest & 1 & $0.376 \pm 0.13$ & 1.515 & 8.373 & 0.005 \\
\hline Date of first egg & 1 & $-0.006+0.01$ & 0.039 & 0.215 & 0.644 \\
\hline Clutch size & 1 & $-0.019 \pm 0.04$ & 0.046 & 0.254 & 0.615 \\
\hline Error & 78 & & 0.181 & & \\
\hline
\end{tabular}


Fig. 2. Simple regression relationship between the distance from the nearest avian predator nest and tarsus length within (A) medium aged coniferous forest (B) deciduous forest (C) pine bogs and young forests and (D) dense mixed forests.
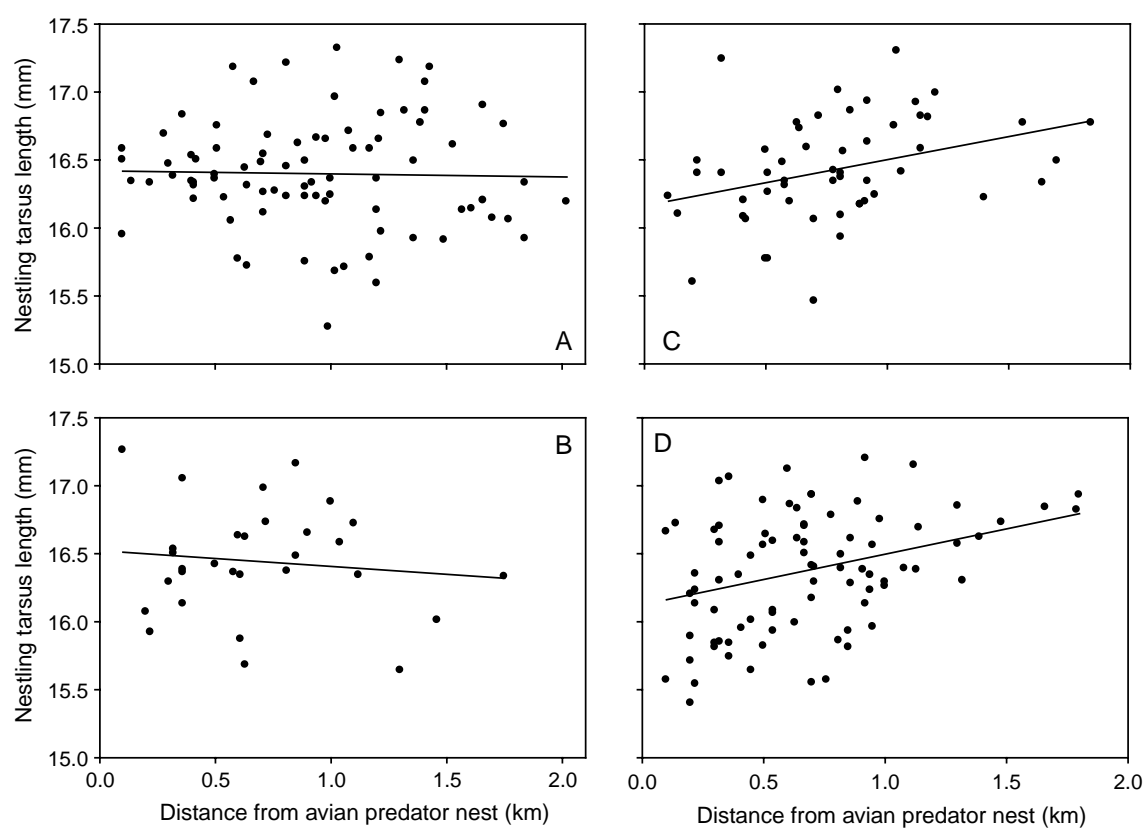

These willow tit results support the concept of a predation risk landscape. Increased frequency of antipredator behaviours, resulting in apprehensive foraging of parents, close to predator nests over the time scale of the nestling period may result in smaller nestlings produced in these nests. For example, willow tit nest defence was shown to vary with distance from sparrowhawk nests (Rytkönen and Soppela 1995), as was the spatial aggregation behaviour and response to mobbing calls of the whole passerine bird community (Forsman et al. 2001, Forsman and Mönkkönen 2001). As an alternative explanation, smaller prey nestlings in the vicinity of breeding predators may result from poor quality prey nesting in these areas. While our results on clutch size variation (and date of first egg) with distance from predator nests suggests this was not a problem, further study into the habitat selection strategies across prey quality will prove valuable. Nevertheless, predation risk can also be considered as an important characteristic of habitat quality affecting individual behaviour and in turn fitness.

One assumption made by the predation risk landscape concept is the even distribution of hunting around the central nesting site by the predator. Individual predators are unlikely to perfectly distribute hunting trips equally around their territory and this is a potential source of heterogeneity to otherwise predictable predation risk gradients. Furthermore, the degree of prey specialisation by individual predators may provide a further source of heterogeneity, although while this may influence the predictability of direct predation risk, its influence on the predictability of indirect (perceived) predation risk is less likely as any encounter with a predator, regardless of its intentions, may be stressful.
Non-lethal predation risk effects, resulting in smaller nestlings, were strongest in two habitat types (about 55\% of nests). We cannot give unequivocal explanations for this trend but two reasons are most likely. The habitat of young forests and pine bogs is structurally the simplest, which matches well with findings that structurally simple habitats emphasise the results of predator-prey interactions by increasing predator encounter rates compared with more diverse habitats (Crowder and Cooper 1982, Gilinsky 1984, Persson and Eklöv 1995, Lewis and Eby 2002). Indeed, earlier studies on predator avoidance of birds relative to breeding predators have occurred in open, structurally simple landscapes e.g. farmlands (Sodhi et al. 1990, Suhonen et al. 1994, Norrdahl and Korpimäki 1998, Hromada et al. 2002, Roos and Pärt 2004) or tundra (Meese and Fuller 1989). On the other hand, strong predation risk effects were found in dense mixed forest, which is clearly at the other end of the complexity continuum. This result may be due to the influence of multiple predators with different hunting tactics (Kotler et al. 1992, Lima 1992). Dense and relatively young forests are also preferred hunting habitats for sparrowhawks (Marquiss and Newton 1982, Selås and Rafoss 1999). The intensity of predator-prey interactions seems thus to be somewhat habitat-dependant varying between structurally open habitats and closed forests but also among different vegetation types within the forest (Forsman et al. 2001).

The observed costs (smaller nestlings) associated with breeding in proximity to avian predators should be reflected in habitat selection or behavioural tactics. However, we observed random placement of willow tit nests with respect to avian predator nests. Geer (1978), working on resident tit species in Britain, observed a 
decrease in nest box occupation in close proximity to sparrowhawk nests. A nesting depression may result from direct predation of prey in territories around predator nests in spring. This was not evident in our willow tit population. Sparrowhawks, however, over-winter in Britain allowing resident species to sample predation risk before making habitat selection decisions. In the north, willow tits are residents that hold territories and may even begin nest excavation before sparrowhawk arrival. It may therefore be too costly (or impossible) to establish new, low predation risk territories, if an avian predator has settled close-by and the benefits of having a life-long permanent territory are cancelled. Indeed, predator avoidance studies in the north largely deal with migrant species (Suhonen et al. 1994, Norrdahl and Korpimäki 1998). Alternatively, the costs associated with close proximity to avian predators may not be that crucial. For example, because we eliminated nest predation, nesting failures were likely due to the death of parent birds. As a result, our data suggests that direct predation did not increase closer to predator nests. Furthermore, nesting in the vicinity of potential predators may even involve benefits. Studies indicate that predators of adult birds may provide protection against destructive nest predators (Norrdahl et al. 1995, Ueta 2001).

In northern boreal forests, migrant passerines have been shown to use resident Parids as positive cues in breeding habitat selection, resulting in increased migrant densities with increasing resident densities (Mönkkönen et al. 1990, Forsman et al. 1998a, Thomson et al. 2003). In these studies, the densities of resident titmice were manipulated prior to migrant arrival and the settling response of migrants was measured. Three possibilities may account for cue-using and the subsequent fitness benefits (Forsman et al. 2002). First, residents may indicate high quality habitats in terms of food abundance, or second, in terms of safety from predators. Third, migrants may benefit from frequent social interactions with residents. Our results suggest that willow tits, due to random nest locations relative to perceived predation risk, are not reliable cues with regards to relatively safe habitats and therefore that a key mechanism of the heterospecific attraction hypothesis is refuted. Nevertheless, residents may still provide reliable cues to optimal habitat when the interactions of many factors are combined. Particularly, there may be social benefits to migrants when associating with resident parids (Forsman et al. 2002, Seppänen et al. 2005). Future work could test the same mechanism using great tits (Parus major L.) which settle later in spring. In fact, different Parid species likely provide cues to different biotic or abiotic factors of relevance to different migrant species.

Lowered fitness related measures in willow tit nests closer to predator nests support the concept of a predation risk landscape. Although predictable gradients in predation risk did not appear to affect the location of willow tit nests, they may be accurately perceived in other prey species (Thomson et al. 2006). This might allow us to predict how non-lethal risk will affect the ecology of species at a far larger temporal and spatial scale than has previously been possible. It further seems likely that the intensity or quality of prey species interactions will vary relative to breeding avian predators. Therefore, by providing predictability to predation risk on a landscape scale, the predation risk landscape concept may allow us to better understand variation in these interactions.

Acknowledgements - We thank the many field assistants helping in the willow tit project. Juli Broggi gave valuable comments on the manuscript. Financial support was provided by CIMO, Univ. of Oulu (Centre of Excellence) and the Academy of Finland (project \#44085).

\section{References}

Adriaensen, F., Dhondt, A. A., Van Dongen, S. et al. 1998. Stabilising selection on blue tit fledgling mass in presence of sparrowhawks. - Proc. R. Soc. B 265: 1011-1016.

Bogliani, G., Sergio, F. and Tavecchia, G. 1999. Woodpigeons nesting in association with hobby falcons: advantages and choice rules. - Anim. Behav. 57: 125-131.

Brotons, L. and Broggi, J. 2003. Influence of morphology on winter residence and recruitment in juvenile coal tits (Parus ater) after the post-fledging period. - Ecoscience 10: $273-$ 282.

Blank, S., Seiter, C. and Bruce, P. 2001. Resampling stats in Excel. - Resampling Stats, Arlington, Virginia.

Burke, S. 2001. Missing values, robust statistics and nonparametric methods. Statistics and data analysis. - LC. GC Europe online supplement 59: 19-24.

Cooper, H. and Hedges, L. V. 1994. The handbook of research synthesis. - Russel Sage Foundation.

Crowder, L. B. and Cooper, W. E. 1982. Habitat structural complexity and the interaction between bluegills and their prey. - Ecology 63: 1802-1813.

Dhondt, A. A., Kempenaers, B. and Clobert, J. 1998. Sparrowhawk predation and blue tit adult annual survival rate. - Ibis 140: $580-584$.

Forsman, J. T. and Mönkkönen, M. 2001. Responses by breeding birds to heterospecific song and mobbing call playbacks under varying predation risk. - Anim. Behav. 62: $1067-1073$.

Forsman, J. T., Mönkkönen, M., Helle, P. et al. 1998a. Heterospecific attraction and food resources in migrants' breeding patch selection in northern boreal forest. - Oecologia 115: 278-286.

Forsman, J. T., Mönkkönen, M., Inkeröinen, J. et al. 1998b. Aggregate dispersion of birds after encountering a predator: experimental evidence. - J. Avian Biol. 29: 44-48.

Forsman, J. T., Mönkkönen, M. and Hukkanen, M. 2001. Effects of predation on community assembly and spatial dispersion of breeding forest birds. - Ecology 82: 232-244.

Forsman, J. T., Seppänen, J-T. and Mönkkönen, M. 2002. Positive fitness consequences of interspecific interaction with a potential competitor. - Proc. R. Soc. B 269: 1619-1623.

Geer, T. A. 1978. Effects of sparrowhawks on nesting tits. - Condor 80: 419-423.

Geer, T. A. 1982. The selection of tits Parus spp. by sparrowhawks Accipiter nisus. - Ibis 124: 159-167.

Gilinsky, E. 1984. The role of fish predation and spatial heterogeneity in determining benthic community structure. - Ecology 65: 455-468. 
Götmark, F. 2002. Predation by sparrowhawks favours early breeding and small broods in great tits. - Oecologia 130: $25-32$.

Gurevitch, J. and Hedges, L. V. 1993. Meta-analysis: combining the results of independent experiments. - In: Scheiner, S. and Gurevitch, J. (eds), Design and analysis of ecological experiments. Chapman and Hall, pp. 378-398.

Hromada, M., Tryjanowski, P. and Antczak, M. 2002. Presence of the great grey shrike Lanius excubitor affects breeding passerine assemblage. - Ann. Zool. Fenn. 39: 125-130.

Jędrzejewska, B. and Jędrzejewski, W. 1993. Summer food of the pygmy owl Glaucidium passerinum in Bialowieza National park, Poland. - Ornis Fenn. 70: 196-201.

Koivula, K., Orell, M. and Rytkönen, S. 1996. Winter survival and breeding success of dominant and subordinate willow tits Parus montanus. - Ibis 138: 624-629.

Korpimäki, E. 1981. On the ecology and biology of Tengmalm's owl (Aegolius funereus) in southern ostrobothnia and suomenselkä, western Finland. - PhD thesis, Univ. of Oulu.

Kotler, B. P., Blaustein, L. and Brown, J. S. 1992. Predator facilitation: the combined effect of snakes and owls on the foraging behavior of gerbils. - Ann. Zool. Fenn. 29: 199206.

Kullberg, C. 1995. Strategy of the pygmy owl while hunting avian and mammalian prey. - Ornis Fenn. 72: 72-78.

Lahti, K., Koivula, K., Orell, M. et al. 1996. Social dominance in free-living willow tits Parus montanus: determinants and some implications of hierarchy. - Ibis 138: 539-544.

Lewis, D. B. and Eby, L. A. 2002. Spatially heterogeneous refugia and predation risk in intertidal salt marshes. - Oikos 96: 119-129.

Lima, S. L. 1992. Life in a multi-predator environment: some considerations for anti-predatory vigilance. - Ann. Zool. Fenn. 29: 217-226.

Lima, S. L. 1998a. Non-lethal effects in the ecology of predator-prey interactions. - Bioscience 48: 25-34.

Lima, S. L. 1998b. Stress and decision making under the risk of predation: recent developments from behavioural, reproductive, and ecological perspectives. - Adv. Study Behav. 27: 215-290.

Lindström, J. 1999. Early development and fitness in birds and mammals. - Trends Ecol. Evol. 14: 343-347.

Marquiss, M. and Newton, I. 1982. Habitat preference in male and female sparrowhawks Accipiter nisus. - Ibis 124: 324 328.

Meese, R. J. and Fuller, M. R. 1989. Distribution and behaviour of passerines around peregrine (Falco peregrinus) eyries of western Greenland. - Ibis 131: 27-32.

Merilä, J. 1997. Expression of genetic variation in body size of the collared flycatcher under different environmental conditions. - Evolution 51: 526-536.

Mönkkönen, M., Helle, P. and Soppela, K. 1990. Numerical and behavioural responses of migrant passerines to experimental manipulation of resident tits (Parus spp.): heterospecific attraction in northern breeding bird communities? - Oecologia 85: 218-225.

Mönkkönen, M., Härdling, R., Forsman, J. T. et al. 1999. Evolution of heterospecific attraction: using other species as cues in habitat selection. - Evol. Ecol. 13: 91-104.

Mönkkönen, M., Tornberg, R. and Väisänen, P. 2000. Kanahaukka voi vähentää lintujen pesiin kohdistuvaa saalistusta suomalaisissa metsämaisemissa. - Suomen Riista 46: 27-36 (in Finnish with English summary).

Morse, D. H. 1977. Feeding behaviour and predator avoidance in heterospecific groups. - Bioscience 27: 332-339.

Müller, J. W. 2000. Possible advantages of a robust evaluation of comparisons. - J. Res. Natl. Inst. Stand. Technol. 105: 551555 .

Newton, I. 1986. The sparrowhawk. - Poyser, Calton.
Nilsson, J.-A. and Gårdmark, A. 2001. Sibling competition affects individual growth strategies in marsh tit, Parus palustris, nestlings. - Anim. Behav. 61: 357-365.

Norrdahl, K. and Korpimäki, E. 1998. Fear in farmlands: how much does predator avoidance affect bird community structure? - J. Avian Biol. 29: 79-85.

Norrdahl, K., Suhonen, J., Hemminki, O. et al. 1995. Predator presence may benefit: kestrels protect curlew nests against nest predators. - Oecologia 101: 105-109.

Orell, M. and Ojanen, M. 1983. Breeding biology and population dynamics of the willow tit (Parus montanus). - Ann. Zool. Fenn. 20: $90-114$.

Orell, M. and Koivula, K. 1988. Cost of reproduction: parental survival and production of recruits in the willow tit Parus montanus. - Oecologia 77: 423-432.

Orell, M., Lahti, K., Koivula, K. et al. 1999. Immigration and gene flow in a northern willow tit (Parus montanus) population. - J. Evol. Biol. 12: 283-295.

Persson, L. and Eklöv, P. 1995. Prey refuges affecting interactions between piscivorous perch and juvenile perch and roach. - Ecology 76: 70-81.

Quinn, J. L., Prop, J., Kokorev, Y. et al. 2003. Predator protection or similar habitat selection in red-breasted goose nesting associations: extremes along a continuum. - Anim. Behav. 65: 297-307.

Roos, S. and Pärt, T. 2004. Nest predators affect spatial dynamics of breeding red-backed shrikes (Lanius collurio). - J. Anim. Ecol. 73: 117-127.

Rosenberg, M. S., Adams, D. C. and Gurevitch, J. 1997. MetaWin. Statistical software for meta-analysis and resampling tests. Version 2.0. - Sinauer Associates.

Rytkönen, S. and Soppela, M. 1995. Vicinity of sparrowhawk nest affects willow tit nest defense. - Condor 97: 1074-1078.

Rytkönen, S., Kuokkanen, P., Hukkanen, M. et al. 1998. Prey selection by sparrowhawks Accipiter nisus and characteristics of vulnerable prey. - Ornis Fenn. 75: 77-87.

Sasvári, L. and Hegyi, Z. 1998. Bird predation by tawny owl (Strix aluco L.) and its effect on the reproductive performance of tits. - Acta Oecol. 19: 483-490.

Scheiner, S. M. 2001. Theories, hypotheses, and statistics. - In: Scheiner, S. M. and Gurevitch, J. (eds), Design and analysis of ecological experiments, 2nd ed. Oxford Univ. Press, pp. $3-13$.

Selås, V. and Rafoss, T. 1999. Ranging behaviour and foraging habits of breeding sparrowhawks Accipiter nisus in a continuous forested area in Norway. - Ibis 141: 269-276.

Seppänen, J.-T., Mönkkönen, M. and Forsman, J. T. 2005. Presence of other species may counter seasonal decline in breeding success - a field experiment. - J. Avian Biol. 36: $380-385$.

Sodhi, N. S., Didiuk, A. and Oliphant, L. W. 1990. Differences in bird abundance in relation to proximity of merlin nests. - Can. J. Zool. 68: 852-854.

Suhonen, J., Norrdahl, K. and Korpimäki, E. 1994. Avian predation risk modifies breeding bird community on a farmland area. - Ecology 75: 1626-1634.

Thomson, R. L., Forsman, J. T. and Mönkkönen, M. 2003. Positive interactions between migrant and resident birds: testing the heterospecific attraction hypothesis. - Oecologia 134: 431-438.

Thomson, R. L., Forsman, J. T., Sardà-Palomera, F. et al. 2006. Fear factor: prey habitat selection and its consequences in a predation risk landscape. - Ecography, in press.

Ueta, M. 2001. Azure-winged magpies avoid nest predation by breeding synchronously with Japanese lesser sparrowhawks. - Anim. Behav. 61: 1007-1012.

Whittingham, M. J. and Evans, K. L. 2004. The effects of habitat structure on predation risk of birds in agricultural landscapes. - Ibis 146: 210-220.

Subject Editor: Jan Lindström 